\title{
Recurrence of thromboembolic disease after discontinuing anticoagulant therapy $A$ study of factors affecting incidence
}

\author{
Leon Michaels ${ }^{1}$ \\ From the Faculty of Medicine, University of Manitoba, Winnipeg 3, Manitoba, Canada
}

On 169 occasions anticoagulant therapy for thromboembolic disease was stopped electively and patients were followed for 16 subsequent weeks. The records of those who remained well and those who suffered a relapse were compared in an attempt to identify factors that might affect liability to thromboembolic relapse.

During the follow-up period there were 37 thromboembolic recurrences, an incidence of 22 per cent. None occurred among the patients in whom the original diagnosis of thromboembolic disease was discarded or when a predisposing cause had ceased to be present. There was an inverse relation between liability to relapse and degree of prothrombin time prolongation.

No significant relation could be shown between liability to relapse and any of the following: sex and age; type and severity of the initiating thromboembolic episode; history of earlier thromboembolic disease or relapse after stopping earlier anticoagulant courses; presence of hypertension, hypercholesterolaemia, or diabetes mellitus; type of anticoagulant drug used, duration of therapy, and method of stopping treatment.

Patients with overt occlusive arterial disease at more than one site had a significantly increased liability to relapse when compared with patients with symptomatic disease at a single site. In the group of 134 subjects receiving anticoagulant therapy for coronary arterial disease, occurrence of a thromboembolic episode during the course of treatment and the presence of angina of effort in the months before it was discontinued were both associated with a significant increase in liability to relapse. It is suggested that, ideally, anticoagulant therapy should be continued indefinitely in any patient whose pattern of disease thus increases the likelihood of a thromboembolic recurrence.

The complications of anticoagulant therapy are such that treatment should not be extended beyond established time limits of usefulness. In men who have suffered a myocardial infarction treatment is of proven value for not more than one or two years (Bjerkelund, 1957; Medical Research Council Working Party, 1959). Four to six months has been suggested as the optimal time for treating transient attacks of cerebral ischaemia (Fisher, I964). However, discontinuing treatment is also not without hazard as there is a high risk of thromboembolic disease recurring. This has been reported in patients who had received anticoagulant drugs for myocardial infarction (Nichol et al., 1958), acute coronary insufficiency (Beamish and Storrie, 1965), transient attacks of cerebral ischaemia

Received ro July 1969.

1 Address for correspondence and reprints: Manitoba Clinic, 790 Sherbrook Street, Winnipeg 2, Manitoba, Canada.
(Siekert, 196I), completed stroke (Marshall, 1963), and embolism secondary to rheumatic heart disease (Carter et al., 1958; Cosgriff, 1953).

If it were possible to predetermine which patients are particularly liable to suffer a relapse, the risks associated with needless prolongation of anticoagulant therapy and the hazards of terminating treatment could both be reduced. The present study was therefore undertaken in an attempt to identify any factors affecting liability to thromboembolic recurrences when anticoagulant therapy is stopped electively.

\section{Patients and methods}

The present investigation was undertaken as an extension of a previous study in which the effects of discontinuing anticoagulant therapy abruptly or gradually were compared (Michaels and Beamish, 1967). It was based on a follow-up of patients who had received treatment with anticoagulant drugs for at least one month and in 
whom such therapy had been stopped electively during the years I964 to I967. All such patients were studied with the exception of those in whom a haemorrhage had occurred during the last three months of treatment. In all, 150 patients were followed. In 132 the effects of stopping a single anticoagulant course, in 17 the effects of stopping two, and in I the effects of stopping three courses were observed. There was therefore a total of I69 follow-up studies (Table I). Tabulation and

\section{TABLE I Indications for anticoagulant therapy}

\begin{tabular}{lc}
\hline Initiating episode & $\begin{array}{c}\text { No. of } \\
\text { studies }\end{array}$ \\
\hline Acute coronary insufficiency & 72 \\
Myocardial infarction & 43 \\
Other coronary arterial disease & 19 \\
Cerebrovascular disease & 15 \\
Thrombophlebitis of leg & 6 \\
Other thromboembolic disease & 9 \\
Thromboembolic disease absent $\dagger$ & 5 \\
\hline Total & 169
\end{tabular}

* Classification difficult, e.g. bundle-branch block present.

† Initial diagnosis discarded.

analysis of the data were based on the total number of studies. This was not thought to have weighted the results in any way, as a preliminary analysis showed no connexion between occurrence of relapses after terminating earlier courses of treatment and liability to recurrence during the follow-up period under study (see Table 2).

The effects on the thromboembolic recurrence rate of the following factors were analysed: sex and age; type and severity of the thromboembolic episode for which anticoagulant therapy was given; extent of vascular disease; history of earlier thromboembolic disease and sequelae of stopping earlier courses of anticoagulant drugs; continuation or otherwise of predisposing causes such as post-operative immobilizing in a patient with thrombophlebitis of a leg; presence or absence of hypertension, hypercholesterolaemia, or diabetes mellitus; occurrence of thromboembolic episodes during the course of treatment and presence or absence of symptoms before its termination; type of anticoagulant drug used, duration of therapy, quality of control, and method of stopping treatment.

Initially the patients were allocated randomly to one of two groups. In one, anticoagulant therapy was 'tailed-off' over a six-week period, and in the other it was stopped abruptly. However, all anticoagulant courses were terminated abruptly after earlier analysis had shown that the method of stopping did not affect the recurrence rate significantly (Michaels and Beamish, 1967). Patients were followed during the six-week 'tailoff' period and for 16 weeks after stopping anti- coagulant therapy. They were asked to report untoward occurrences immediately. Otherwise they were reassessed four weeks after stopping treatment and at the end of the follow-up period.

Data were coded for card punching and computer analysis. The significance of differences in the recurrence rates observed in the paired subgroups was estimated by the $\chi^{2}$ method, Yates' modification being used when any of the numbers being compared was less than ro.

The following definitions were employed.

The relevant anticoagulant course is any course the effects of whose elective termination is part of the present study.

Earlier anticoagulant courses are any whose termination, elective or otherwise, preceded the start of the relevant course by at least one month. Breaks of less than one month were regarded as temporary interruptions in the relevant anticoagulant course.

The initiating episode is the one for which the relevant anticoagulant course was prescribed.

An earlier episode is any thromboembolic incident preceding the initiating episode by at least three months. An occurrence closer in time and similar in character was regarded as part of the initiating episode.

An intercurrent episode is any major thromboembolic occurrence during the relevant anticoagulant course.

The observation period is the six-week 'tail-off' period and the 16 weeks that followed complete stopping of anticoagulant therapy.

The last three blood pressures recorded during the relevant anticoagulant courses were averaged and hypertension defined as a mean systolic blood pressure greater than 170 and a diastolic greater than $100 \mathrm{~mm}$. Hg. The highest recorded serum cholesterol was used as a basis for comparisons. Diabetes mellitus was diagnosed if, during a stress-free period, the true plasma glucose exceeded $100 \mathrm{mg}$. $/ 100 \mathrm{ml}$. fasting or 120 $\mathrm{mg} . / 100 \mathrm{ml} .2$ hours after oral administration of $50 \mathrm{~g}$. glucose.

\section{Results}

In 33 patients minor symptoms present before stopping anticoagulant therapy continued subsequently, or new symptoms developed which were considered insufficient to warrant resuming treatment. For purposes of comparison these patients were grouped with the subjects who remained symptom free.

There were three major recurrences in the 'tail-off' period and 34 in the following 16 weeks, giving a total of 37 and a recurrence rate of 22 per cent. Seven patients died, one from a stroke and six from cardiac recurrences, either before anticoagulant therapy could be resumed or within a few days of its being restarted. There were 30 patients who survived the recurrence and in whom long-term anticoagulant therapy was resumed.

No relation could be detected between 
sex and age on the one hand and the recurrence rate on the other (Table 3 ). It was 23 per cent in patients receiving anticoagulant therapy for coronary arterial disease and 20 per cent, or almost the same, in subjects with cerebral arterial disease. Within the group with coronary arterial disease, the recur-

TABLE 2 Relation of disease pattern to recurrence rate

\begin{tabular}{|c|c|c|c|}
\hline & \multirow{2}{*}{$\begin{array}{l}\text { No. } \\
\text { at } \\
\text { risk }\end{array}$} & \multicolumn{2}{|c|}{ Recurrences } \\
\hline & & No. & $\%$ \\
\hline \multicolumn{4}{|l|}{ Initiating episode } \\
\hline Coronary & I34 & 31 & 23 \\
\hline Cerebral & 15 & 3 & 20 \\
\hline \multicolumn{4}{|l|}{ Previous history } \\
\hline Earlier episode & 91 & 24 & 25 \\
\hline No earlier episode & 78 & 13 & 17 \\
\hline $\begin{array}{l}\text { Previous anticoagulant course } \\
\text { No previous anticoagulant }\end{array}$ & 46 & 14 & 30 \\
\hline $\begin{array}{l}\text { No previous anticoagulant } \\
\text { course }\end{array}$ & 123 & 23 & 19 \\
\hline \multicolumn{4}{|l|}{ Coronary initiating episode } \\
\hline Acute coronary insufficiency & 72 & $2 \mathrm{I}$ & 29 \\
\hline Myocardial infarction & 43 & 7 & 16 \\
\hline Complicated & 36 & 6 & 17 \\
\hline Uncomplicated & 97 & 25 & 25 \\
\hline \multicolumn{4}{|l|}{ Intercurrent episode } \\
\hline Present & 23 & 12 & $44^{\star}$ \\
\hline Absent & III & 19 & $19^{\star}$ \\
\hline \multicolumn{4}{|l|}{ Angina at end of course } \\
\hline Present & 36 & I6 & $44^{\star}$ \\
\hline Absent & 97 & 15 & $15^{\star}$ \\
\hline \multicolumn{4}{|l|}{ Overt occlusive arterial disease } \\
\hline Widespread & 37 & 14 & $38 \star$ \\
\hline Localized & 117 & 23 & $20 \star$ \\
\hline
\end{tabular}

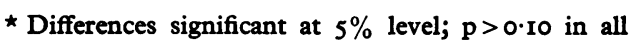
other comparisons. In this and succeeding Tables numbers being compared in the various subgroups may not add up to the corresponding population totals. This results from difficulty in classifying a minority of patients in connexion with each comparison.

TABLE 3 Relation of recurrence to sex and age

\begin{tabular}{llccc}
\hline & Age $(y r)$. & $\begin{array}{l}\text { No. of } \\
\text { subjects }\end{array}$ & \multicolumn{2}{c}{ Recurrences } \\
\cline { 3 - 5 } & & & No. & $\%$ \\
\hline Men & $63.6 \pm 13.0$ & 116 & 27 & 23 \\
Women & $61.9 \pm 12.4$ & 53 & 10 & 19 \\
With recur- & & & & \\
$\quad$ rence & $64.9 \pm 12.2$ & 37 & - & - \\
Without & & 132 & - & - \\
$\quad$ recurrence & $61.9 \pm 12.4$ & 132 & 5 & 24 \\
& $<50$ & 21 & 16 & 18 \\
Age (yr.) & $50-69$ & 88 & 16 & 27 \\
& 70 and over & 60 & & \\
\hline
\end{tabular}

rence rate was not related either to the type or to the severity of the initiating episode. Comparison of patients with and without a history of earlier episodes of thromboembolic disease showed that the former had a higher relapse rate than the latter, but the differences did not approach significance. The recurrence rate was not increased significantly in the group with a history of relapse after stopping an earlier anticoagulant course (Table 2). Furthermore, the time elapsing between the stopping of an earlier course and the onset of the initiating episode was not related in any way to the recurrence rate.

In contrast, an intercurrent episode affected the recurrence rate significantly in the patients receiving anticoagulant drugs for coronary arterial disease (Table 2). This was irrespective of the time elapsing between its occurrence and the termination of the relevant course of therapy, which, with one exception, was never less than 4 months. The presence of angina pectoris at the end of the course was also associated with a significantly increased risk of a recurrence during the observation period (Table 2). Patients with angina, even if mild and occurring on effort only, had an almost threefold risk of relapse when compared with patients who were completely pain free during the last months of treatment.

Widespread occlusive arterial disease, with symptomatic and objective evidence of such at two or more widely separated sites, was associated with a significantly increased risk of relapse (Table 2). Furthermore, the incidence of fatal relapses was significantly greater in this group, accounting for six of the seven deaths occurring during the followup period. Hypertension, hypercholesterolaemia, and diabetes mellitus did not affect the recurrence rate significantly (Table 4). In five patients the initial diagnosis of thromboembolic disease was later abandoned as

TABLE 4 Relation of 'aggravating factors' to recurrence rate

\begin{tabular}{|c|c|c|c|c|}
\hline & & \multirow{2}{*}{$\begin{array}{l}\text { No. } \\
\text { at } \\
\text { risk }\end{array}$} & \multicolumn{2}{|c|}{ Recurrences } \\
\hline & & & No. & $\%$ \\
\hline $\begin{array}{l}\text { Hyper- } \\
\text { tension }\end{array}$ & $\left\{\begin{array}{l}\text { Present } \\
\text { Absent }\end{array}\right.$ & $\begin{array}{r}51 \\
118\end{array}$ & $\begin{array}{l}\text { II } \\
26\end{array}$ & $\begin{array}{l}22 \\
22\end{array}$ \\
\hline $\begin{array}{l}\text { Serum } \\
\text { choles- } \\
\text { terol }\end{array}$ & $\left\{\begin{array}{l}>300 \mathrm{mg} \cdot / 100 \mathrm{ml} . \\
<250 \mathrm{mg} \cdot / 100 \mathrm{ml} .\end{array}\right.$ & $\begin{array}{l}20 \\
52\end{array}$ & $\begin{array}{l}4 \\
5\end{array}$ & $\begin{array}{l}20 \\
\text { II }\end{array}$ \\
\hline $\begin{array}{l}\text { Diabetes } \\
\text { mellitus }\end{array}$ & $\left\{\begin{array}{l}\text { Present } \\
\text { Absent }\end{array}\right.$ & $\begin{array}{r}20 \\
109\end{array}$ & $\begin{array}{r}7 \\
19\end{array}$ & $\begin{array}{l}35 \\
17\end{array}$ \\
\hline
\end{tabular}


erroneous. In none of these was stopping anticoagulant treatment followed by a thromboembolic episode. Furthermore, there were no recurrences in the group of II patients in whom a predisposing cause had ceased to be present.

The results of stopping treatment were not related to the type of anticoagulant used (Table 5) or to the length of the relevant

TABLE 5 Relation of anticoagulant regimen to recurrence rate

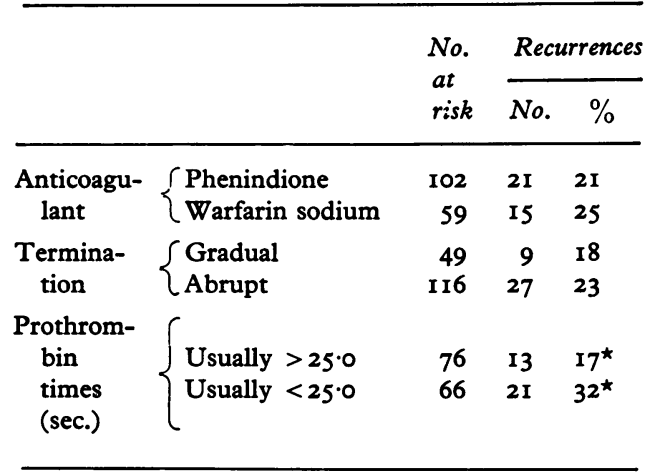

$\star 0.07>p>0.06 ; p>0.10$ in other comparisons.

course, whose median duration was 15 months in the group of patients who relapsed, and 13 months in the group who did not. As reported earlier (Michaels and Beamish, 1967), there was no significant relation between liability to relapse and the method of termination, gradual or abrupt. There was, however, a possible connexion between intensity of treatment and the recurrence rate (Table 5).

The three recurrences in the 'tail-off' period occurred when the anticoagulant dosage had been reduced to one-third or less of the previous maintenance level. The recurrence rate in the first week after stopping treatment was higher than at other times, but only slightly so, and there was no pattern to the decline during the follow-up period (Fig.).

\section{Discussion}

The laboratory evidence for a state of rebound hypercoagulability after stopping anticoagulant treatment is conflicting (Cate et al., I954; Cotton and Wade, 1964; Kazmier et al., 1965; Miller and Bayer, 1960; Poller and Thomson, 1964), and the clinical evidence inconclusive. In many studies, discontinuing anticoagulant therapy was followed by a high recurrence rate of thromboembolism (Beamish and Storrie, 1965; Nichol et al.,

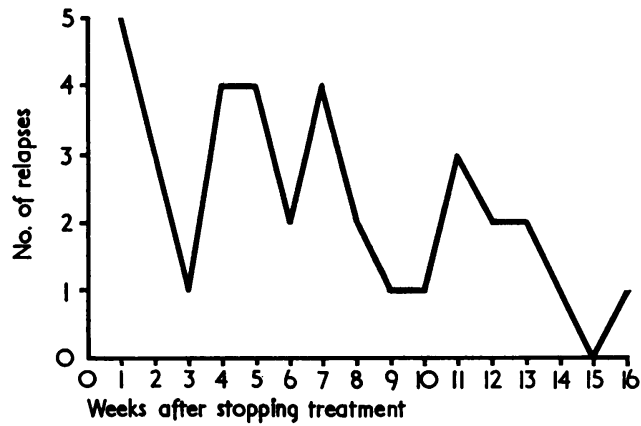

FIG. Relation of relapses to the stopping of anticoagulant treatment.

1958; Siekert, I961; Marshall, 1963; Carter et al., 1958; Cosgriff, 1953). When therapy had been of apparent benefit this could be attributed either to rebound hypercoagulability or to a suppressed tendency to thromboembolism becoming manifest when the protective effects of treatment were withdrawn. A tendency to recurrence could only be ascribed to a hypercoagulable state alone when therapy had been without benefit, and treated and control patients remained as comparable at the end of treatment as at the start. Marshall (1963) so interpreted his finding that, after stopping treatment, patients with a completed stroke had a recurrence rate greater than that of untreated controls. However, Enger and Bøyersen (1965) found that in patients receiving therapy for cerebral infarction, the post-treatment recurrence rate was not, in fact, higher than in untreated controls.

The present findings provide little or no support for the concept that rebound hypercoagulability is an important cause of recurrences. The preponderance of relapses during the first week after discontinuing therapy could be attributed equally well to the underlying disease 'catching up' and was in any case very slight. Differences between the site of the initial episode and the site of relapse were exceptional. Over 90 per cent of patients receiving anticoagulant drugs for coronary arterial disease had relapses involving the coronary circulation. It is not surprising that a few recurrences affected other systems as there is close association between coronary arterial disease and degenerative arterial disease elsewhere in the body (Friedman, Loveland, and Ehrlich, 1968). There were no recurrences among the 16 patients in whom preceding vascular disease played little or no part in causation of the initiating episode, 5 in whom the initial diagnosis of thromboembolic disease was discarded, and 
II in whom a predisposing cause had ceased to be present. In contrast, a significant link between widespread arterial disease and recurrence rate was found. Length of treatment and liability to relapse were not related. Abrupt termination of treatment did not increase the likelihood of relapse and all recurrences were single. The present findings suggest that in the genesis of relapse any transient hypercoagulable state is of much less importance than the state of the vascular tree.

Irrespective of cause, the relapse rate after stopping anticoagulant therapy electively is high, and this has to be considered when deciding whether to stop treatment. To be able to recognize any subgroups with either a high or a low risk of recurrence would be of considerable practical value. Kamath and Thorne (1969) suggested that such categorizing is not possible, but their data were not analysed with respect to the factors that the present study showed to be of significance.

The present findings indicate that anticoagulant therapy can be stopped with impunity if an initial diagnosis of thromboembolism is later abandoned as erroneous, or if a former predisposing cause has ceased to be present for about four months. Neither an earlier thromboembolic episode nor a relapse after ending an earlier anticoagulant course need affect a decision to terminate treatment.

The absence of a demonstrable association between hypertension, hypercholesterolaemia, and diabetes mellitus on the one hand and the recurrence rate on the other may have been due to insufficient numbers in each category, but it is possible, too, that treatment of these conditions ameliorates any effects on the natural history of thromboembolic disease. For practical purposes, the findings suggest that their presence need not affect a decision to discontinue anticoagulant therapy.

A near significant association between intensity of treatment and recurrence rate was found in the present study, highlighting the need for treatment to be intense enough to prolong the prothrombin time consistently to at least twice the control time. On occasion, it is necessary to decide whether to discontinue therapy in a patient who has received anticoagulant drugs for many years. The present findings contrast with those of Kamath and Thorne (1969), and suggest that, if otherwise indicated, it is reasonable to stop such treatment, as long duration of therapy does not increase the risk of relapse. As shown previously (Michaels and Beamish, 1967), treatment can be stopped abruptly. This has the advantage of simplicity and eliminates the danger of haemorrhage during the 'tail-off' period.

In patients with arterial disease, no relation could be shown between the recurrence rate and the occurrence of myocardial infarction, shock, rhythm disturbance, or heart failure during the initial episode. These factors need not, therefore, influence a decision to stop treatment.

There is no consensus to date about the optimal duration of a course of anticoagulant therapy for patients with acute cerebrovascular insufficiency. The present series includes I4 such patients, all but one with vertebro-basilar insufficiency. Treatment was stopped after an average of 19 months, and there were no episodes of cerebrovascular insufficiency or stroke during the observation period. The three thromboembolic recurrences were coronary in nature and occurred in patients with coexisting angina of effort. The findings now being reported suggest, therefore, that elective stopping of anticoagulant therapy after one to two years is justified in patients with vertebro-basilar insufficiency provided that they have no manifestations of occlusive arterial disease elsewhere.

Three circumstances were found to be associated with a significantly increased liability to relapse. First, patients with widespread overt occlusive arterial disease had a recurrence rate almost double that observed in patients with disease at only one site, and the relapses that did occur were more serious. Secondly, in the group with coronary arterial disease, patients with persistent angina of effort were found to have a significantly higher recurrence rate than those who were free of pain during the last months of treatment. This increased liability to relapse was not related to the severity of the angina, and is in accord with Borchgrevink's (1962) finding that intensive therapy with anticoagulant drugs is valuable in patients with uncomplicated angina pectoris. Thirdly, patients with coronary arterial disease and an intercurrent thromboembolic episode during treatment were more liable to relapse than patients with no such history. This difference was noted despite therapy usually being continued for at least six months after an intercurrent episode of acute coronary insufficiency and for at least two years after an intercurrent myocardial infarction. The findings suggest that, ideally, treatment should be continued indefinitely in a patient with overt arterial disease at more than one site, and in a patient with coronary arterial disease who has either a history of an intercurrent episode 
or angina of effort. Application of these criteria to the population under study would have resulted in treatment being continued on 73 occasions, the recurrence rate in this group being 36 per cent. On the remaining 96 occasions the decision to discontinue anticoagulant therapy would have remained the same. The relapse rate was only i I per cent in this 'low risk' group.

I would like to thank Dr. R. E. Beamish for permission to study patients under his care, Dr. D. F. Patton for help with analysis of the data, and Mr. D. J. Protti for the data processing.

\section{References}

Beamish, R. E., and Storrie, V. M. (1965). Anticoagulant therapy in impending myocardial infarction. In Anticoagulant Therapy in Ischemic Heart Disease: Miami Heart Institute International Symposium, 1964, p. 4. Ed. by E. S. Nichol et al. Grune and Stratton, New York.

Bjerkelund, C. J. (1957). The effect of long term treatment with dicoumarol in myocardial infarction. A controlled clinical study. Acta Medica Scandinavica, Suppl. 330.

Borchgrevink, C. F. (1962). Long-term anticoagulant therapy for angina pectoris: a follow-up study. Lancet, 1, 449.

Carter, S. A., McDevitt, E., Gatje, B. W., and Wright, I. S. (1958). Analysis of factors affecting the recurrence of thromboembolism off and on anticoagulant therapy. American fournal of Medicine, 25, 43.

Cate, W. R., Jr., Sadler, R. N., Seitzman, D. M., and Light, R. A. (1954). Heparin rebound: a clinical and experimental study. American Surgeon, 20, 813.

Cosgriff, S. W. (1953). Chronic anticoagulant therapy in recurrent embolism of cardiac origin. Annals of Internal Medicine, 38, 278.

Cotton, R. C., and Wade, E. G. (1964). Effect of sudden withdrawal of 'long-term' anticoagulant therapy on the heparin resistance and plasma fibrinogen level. Clinical Science, 26, 337.

Enger, E., and Bøyersen, S. (1965). Long-term anticoagulant therapy in patients with cerebral infarction: a controlled clinical study. Acta Medica Scandinavica, Suppl. 438.

Fisher, C. M. (1964). Discussion. In Cerebral Vascular Disease: Transactions of the 4th Conference, p. 192. Ed. by C. H. Millikan, R. G. Siekert, and J. P.
Whisnant. Grune and Stratton, New York and London.

Friedman, G. D., Loveland, D. B., and Ehrlich, S. P., Jr. (1968). Relationship of stroke to other cardiovascular disease. Circulation, 38, 533.

Kamath, V. R., and Thorne, M. G. (I969). Ischaemic heart-disease and withdrawal of anticoagulant therapy. Lancet, I, 1025.

Kazmier, F. J., Spittell, J. A., Jr., Thompson, J. J., Jr., and Owen, C. A., Jr. (1965). Effect of oral anticoagulants on factors VII, IX, $X$ and II. Archives of Internal Medicine, 115, 667.

Marshall, J. (1963). Rebound phenomena after anticoagulant therapy in cerebrovascular disease. Circulation, 22, 329.

Medical Research Council Working Party (1959). An assessment of long-term anticoagulant administration after cardiac infarction. British Medical fournal, 1, 803.

Michaels, L., and Beamish, R. E. (1967). Relapses of thromboembolic disease after discontinued anticoagulant therapy. American fournal of Cardio$\log y, 20,670$.

Miller, K. D., and Bayer, W. L. (1960). Prothrombin rebound - a response to dicoumarol. In Annual Report, Division of Laboratories and Research, N.Y. State Dept. of Health, p. 43.

Nichol, E. S., Keyes, J. N., Borg, J. F., Coogan, T. J., Boehrer, J. J., Mullins, W. L., Scott, T., Page, R., Griffith, G. C., and Massie, E. (1958). Long-term anticoagulant therapy in coronary atherosclerosis. American Heart fournal, 55, 142.

Poller, L., and Thomson, J. M. (1964). Evidence for 'rebound' hypercoagulability after stopping anticoagulants. Lancet, 2,62 .

Siekert, R. G. (1961). In Cerebral Vascular Disease: Transactions of the 3rd Conference, p. 94 . Ed. by C. H. Millikan, R. G. Siekert, and J. P. Whisnant. Grune and Stratton, New York and London.

\section{Addendum}

Since this paper was submitted, the report of an International Anticoagulant Review Group has appeared (Lancet (1970), I, 203. The results of the investigation now being reported take on added significance in view of the findings of this Group. It showed that in patients receiving prolonged anticoagulant therapy for a myocardial infarction, the treatment had its greatest value in patients with prolonged angina or a history of a second infarction. 